\title{
SMART MECHATRONIC SYSTEMS FOR THE DEVELOPMENT OF INDUSTRY 4.0 IN ROMANIA
}

\author{
Gheorghe Gheorghe \\ ${ }^{1}$ National Institute of Research and Development for Mechatronics and Measurement \\ Technique - INCDMTM, Bucharest, Romania \\ Email: geocefin@yahoo.com
}

\begin{abstract}
The scientific work focuses in the synthesis on the substantial importance of Mechatronics and Cyber-MixMechatronics in the development of Industry 4.0 in Romania through fundamental concepts and solutions for integration and implementation in the structures of intelligent industrial architectural components and assemblies. The scientific paper presents comparatively the stage of Industry 4.0 in Europe and Romania and especially the European and national policies of this new Global and Synergic Industry. There are mentioned the development stages of Industry 4.0, intelligent components and industries and more for the digitization of all industrial structures of industrial enterprises for intelligent and cybernetic manufacturing. Mechatronic and cyber-mixmechatronics concepts and solutions are addressed to simulate, develop and support Industry 4.0 in Romania.
\end{abstract}

Keywords: Industry 4.0 (Fourth Industrial Revolution); Industrial Digitization; Mechatronics and Cyber-Mixmechatronics; Intelligent Concepts and Solutions; Mechatronic and Cyber-Mixmechronic Systems; Integrated System of Intelligent Systems; Digital Trust; IoT Cyber-Physical Systems; IoT Cyber-MixMechatronic Systems; Collaborative Digital Applications, etc..

\section{Introduction}

At european union level, new concepts have been created to stimulate, develop and support industry 4.0 as a basis for economic competitiveness development of the member countries, as key lessons for european and national policies.Stimulating industry 4.0 is for the eu economy.At present and in the future, advanced technologies fuel the so-called "fourth industrial revolution" with the strategic goal of transforming eu industries and creating a massive growth of the european economy through the greatest digital opportunity for existing industry and enterprise not by creating new industries.

This means adapting advanced digital technologies to existing European and national enterprises, which is now the greatest challenge and paradigm to achieve the best positive results.

Development of Industry 4.0 is the key to the development of the European Union.

Based on recent European studies on industry development through the Fourth Industrial Revolution called Industry 4.0, it was stated with reasons of hope that $76 \%$ of respondents see digital technologies as an opportunity, while $64 \%$ of companies investing in digital technologies have already generated positive results.

Support for Industry 4.0 in Europe is achieved through national policies of member countries.
In this respect, in response to these challenges and paradigm solutions, most EU governments have adopted, as a matter of priority, the policies of the large-scale Industry 4.0 to increase productivity and competitiveness and to improve high-tech skills of the workforce.

As a positive example, the key components of the national policies of Industry 4.0 to Spain, the UK, France, Italy, Germany, the Czech Republic, Sweden and the Netherlands can be nominated through a substantial (public and private) financial targeting approach and target audience (industry and production base, SMEs, manufacturers, large companies, universities, research centers, academic and industrial research, service sector, trade unions, etc.).

As a positive example, the key components of the national policies of Industry 4.0 to Spain, the UK, France, Italy, Germany, the Czech Republic, Sweden and the Netherlands can be nominated through a substantial (public and private) financial targeting approach and target audience (industry and production base, SMEs, manufacturers, large companies, universities, research centers, academic and industrial research, service sector, trade unions, etc.).

The key features of National Industry 4.0 policies are global and synergistic.

These are integrated into Industry 4.0's global and synergistic policy frameworks, which are part of a 
general and strategic framework reflecting the industry's 4.0 priority status in Europe.

In particular, they are much broader frameworks or strategies, which prioritize the vision and general approach of research, innovation and industry policies.

Each developed European country, based on the new European concept of Industry 4.0, develops its related national policies, as follows:

- the French industry: "Industrie du Future (IdF)" is linked to the new Industrial France (NFI), where significant underinvestment and problems in developing competitive digital industries have been the driving force behind policy;

- Italian industry: through "Cluster Factory Inteligent Italian (CFI)" ), drew up against the Italian Innovation Roadmap, a wider strategy on Italy's socioeconomic challenges such as climate change, resource scarcity, demographic developments, etc.

- the Dutch industry: identifies very tangible reasons for launching initiatives;

the Netherlands industries: through the relatively low labor-related employment share, has led to the creation of a smart industry;

- the Netherlands industries: through the relatively low labor-related employment share, has led to the creation of a smart industry;

- industries of other European countries through a political initiative with a direct result of a general national framework, strategy and / or agenda;

- the German industry has created Industry 4.0 through ten major future projects under the HighTech 2020 Strategy Action Plan.

- the Spanish industry has developed a digital part of the Industrial Sector Consolidation Agenda, which has gradually transformed into Connect Industry 4.0.

- the British industry has advocated a policy strategy for the establishment of technology centers in different industries;

- the Romanian industry is based on the National Development Strategy of Romania 2015-2020 and 2020-2030, the National Competitiveness Program 2015-2020;

and the Mecatron Group Initiative, to MMACA, to develop the Industry Development Strategy 4.0.

Industry 4.0 applies strategic focus and industry / technology focus:

In the first stage, sector / technology focus within Industry 4.0 includes a distributed local implementation structure such as Transport, IoT, Artificial Intelligence, Block Data, PC Hardware, Digital Trust, Intelligent Cities, IoT Cyber-Physical Systems , IoT Cyber-Mechatronics and CyberMixMechatronics systems, digital platforms, collaborative applications, sectoral implementation in aerospace, automotive, chemical, nuclear, pharmaceutical, electronics, mechatronics, etc.

In the second stage, strategic focusing within Industry 4.0 includes an overall architectural structure, industry and enterprise-specific, in strategic implementation.

\section{Strategic Policies of the Industry 4.0}

In summary, the strategic policies for Industry 4.0 are well defined and look great, overlapping with the objectives and targets pursued, notably consolidation of the country and new industrial competitiveness, modernization and better assurance of the sustainable growth of the intelligent production sector.

Most European countries, especially Germany, are focusing on gaining greater productivity and increased efficiency.

Thus, providing of the future generation of technologies (such as Italy and the UK), the development of new industrial process improvement products and services (such as Germany and Italy) that give support to SMEs for innovation and commercialization (such as the UK, France and Spain), are among the most prominent objectives.

In Europe, Industry 4.0 policies have common goals, but all have elements that give each policy a small influence, as follows:

- the French initiatives, presents a market-based approach to the companies participating in the program;

- Spanish initiatives, presents a cost-based approach based on the line of action and the type of company that varies between a $25 \%$ to $70 \%$ coverage cost; The French IdF combines a wide range of financing, instruments (eg, loans and tax incentives with private investment in R \& D);

Swedish initiatives (Sweden P2030), presents a strong leadership and funding approach by industry that ensures the long-term impact and sustainability of industry;

- British initiatives focus on providing technology and expertise on an industrial scale, for companies, to eliminate risk in innovation through technology centers.

Focusing and impact area involves research on Industry 4.0, giving priority to speeding up deployment and application of Industry 4.0 technologies focusing on the development of new technologies that address manufacturing innovation challenges such as the Internet of Things (IoT), Cyber-Physical Systems (CPS) / CyberMixMechatronics Systems (CMMS).

It is noted that models are lacking and Industry 4.0 initiatives tend to be relatively open in terms of the application of specific technologies or sectoral domains in terms of increasing the sustainability of production as a common impact area in terms of offering information and support for implementation, and better business and opportunity exploitation, greater flexibility in 
production volume, efficiency, costs and customer satisfaction as the main expected effects.

The exemples of funding sources for Industry 4.0 contain a structure of public sources, private sources and public-private sources, as follows:

- Industry 4.0 in Germany, public-private sources, ratio $2: 1 \div 5: 1$;

- industry for future, in France, public sources (10 bil. Euro) and private sources, ratio 5:1;

- spanish industry, manufacturing of high value (CATAPULT) Spain, public sources (367 bil. Euro) in multiannual financing and private sources, ratio: 17:1.

The results of Industry 4.0 in Europe have tangible results and qualitative and quantitative results as a result of national policies for Industry 4.0 in Europe (eg France, the Netherlands, Sweden and the United Kingdom), as follows:

- in France, through IDF, more than 800 loans for enterprises and 3400 of diagnosis were achieved;

- in Sweden, through P2030, were financed 30 projects with the participation of over 150 enterprises;

- in Germany, through I 4.0 initiative, has highlighted outstanding qualitative results such as the segregation of small industries, the transformation of research into practical applications, and the creation of platform reference architectures with more than 150 members;

- In the UK, through HVMC, were initiatives with clear digitization, monitoring and evaluation cycles, with the value of innovation work above $123 \%$ of the initial target (2013-2015)

- etc.

- In Romania, there are initiatives to address Industry 4.0 , in stages, in a complementarity with the initiatives of European countries, as follows:

- developing the Strategy for Industry 4.0 in the period 2019-2023 and 2023-2027 and in the future;

- Integration of the Industry Strategy 4.0 within the National Strategies and Programs elaborated for the years 2019-2023 and 2023-2027 and in the future;

- Development of Strategic Industry Programs and Plans 4.0 (by industry / pilot enterprises), (eg Intelligent Production Program 2030, National University School of Digitized Production, etc.);

- Implementing the Industry Strategy 4.0 for the 2019-2023 and 2023-2027 periods and in the future;

- Implementation of Strategic Industry 4.0 Programs and Plans;

- Implementation of Industry 4.0 Initiatives and related and complementary areas;

- development of technologies and infrastructures specific to Industry 4.0; and so on.

\section{Approach to the Industry Strategy 4.0, through the Mechatron Group}

Industrial production related to Industry 4.0 will develop in symbiosis with the modern technique of mechatronics, cyber-mixmechatronics, information and communication.

The technical basis for achieving this goal is the general and complex problem of the digitization of the industry with the integration of intelligent mechatronics, cyber-mixmechatronics, informational and communication systems and the acquisition of related and adequate competences of human resources.

Thus, in their entirety, they make it possible for Industry 4.0, a smart, self-organized production where people (operators), machines, installations, logistics and the product (as output value in the value chain) communicate and cooperate with each other, directly together.

Interconnection / integration will make it possible to jump from supervising a small production segment into self-organization of a whole chain to an enterprise level.

The network will need to include all phases of a product: from idea, through design and production processes, including logistics, product and service usage to recycling.

This fourth industrial revolution is fundamentally different from its predecessors. It would be impossible to define it without using the terms "cyber-physical systems / cyber-mixmechatronics systems" or "cloud computing".

It is a revolution of networks, platforms, people and digital technology.

Industry 4.0 focuses on end-to-end digitization of all physical assets and processes as well as integration into digital ecosystems with partners in the value chain.

The great industrial revolution depends on small technological revolutions in various areas:

Applying information and communications technology to digitize information and integrate systems from design to product development, manufacturing and use.

New software technologies for modeling, simulation, virtualization and digital manufacturing.

Develop Cyber-Physical Systems and CyberMixMechatronics Systems to monitor and control physical processes.

The evolution of 3D printers and additive manufacturing to simplify manufacturing.

Decision support for human operators, the emergence of intelligent tools and assistance using augmented reality. New forms of human-machine interaction. Many of these technologies have been available for a few years, and others are not yet ready for use on a large scale. 
Based on the above mentioned, the MECATRON GROUP, consisting of the National Institute for Research Development for Mechatronics and Measurement Technique - INCDMTM, the Innovative Strategic Cluster for the Mechatronics and Cyber-Mix Mechatronics Intelligent Field of Specialization "MECATHREC", the Employing Association of the Fine Mechanics, Optics and Mechatronics in Romania - APROMECA Cluster Management Entity, Relay Center for Technology Transfer and Consultancy CRTTC of INCDMTM, Mechatronics Industry Competitiveness Pole - INMECHATRON and Training and Evaluation Centers for Intelligent Mechatronics have been designed and developed since 2010 , concepts, syntheses, principles, models, intelligent architectures, modular constructions and mechatronic products and Cyber-MixMecatronics for Industry 4.0, currently many of which are already technologically transferred and implemented in Industry (eg Automobile Industry - SC Automobile Renault-Dacia S.A Piteşti, in the Medical Industry Laser Selection Sintering Technology; in the Aerospace Industry - Metering Systems by Telemetry of Positioning and Relative Distances between Microsatellites; in Intelligent Agricultural Industry Robots in Drone Integrated Systems; etc.), economy and society.

MECATRON GROUP together with national consortia, consortium having entities such as the National Research Institute, Advanced Research Universities, innovative SME's, etc. and structures at European level that include research entities such as Universities, Research Institute, Research Firms and SME's.
They have designed, developed and proposed in various national and international research programs, large and complex research projects for various national and international programs, including Horizon 2020.

The contribution of Intelligent Mechatronics and Cyber-MixMechatronics concepts and constructions to Industry 4.0 is made to a substantial extent on the systems and system parts of intelligent manufacturing products and processes and less the industrial enterprise mix.

In order to develop and support Industry 4.0, the Romanian conception is based on two structural steps, namely: digitization and cybernetization of the components of the architectural ensemble of industry (Industrial Enterprise, Firm, SME's) and digitization of the architectural enterprise ensemble (from input sizes to output sizes).

\section{Examples of Original Concepts and Original Solutions for Industry Digitalization, based on the Development and Integration of Mechatronics and Cyber Mechatronics as XXI Century Sciences}

Original concepts and of intelligent mechatronics systems and cyber mechatronics integrative

$>$ Smart mechatronics system and cybermixmechatronics intehrative of control (fig. 1)

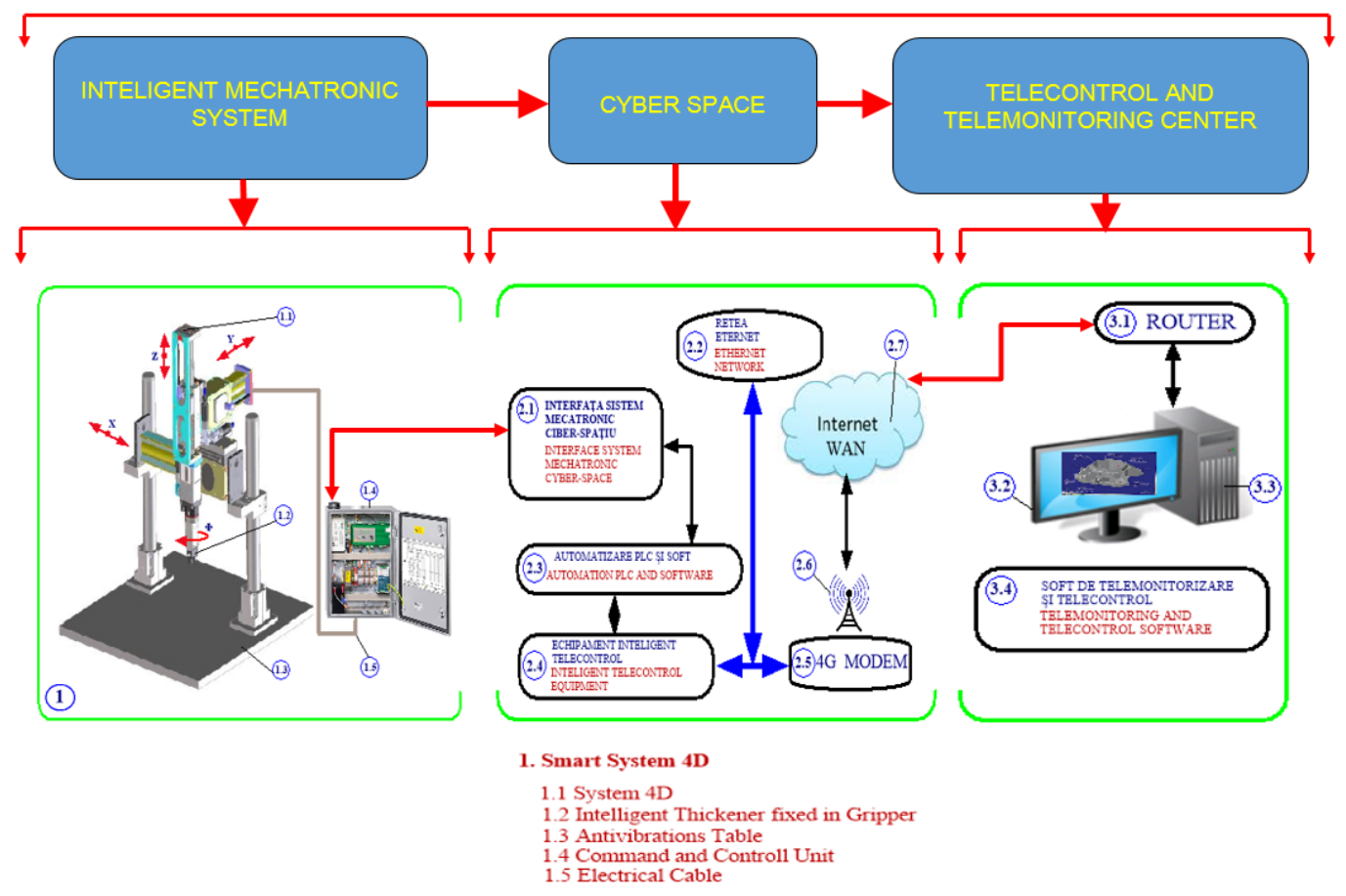

Figure 1: Smart mechatronics system and cyber-mixmechatronics intehrative of control 
$>$ Smart mechatronics and cyber- and tightness measurement for cast parts in mixmechatronics integrative system for verification automotive industry (fig. 2).

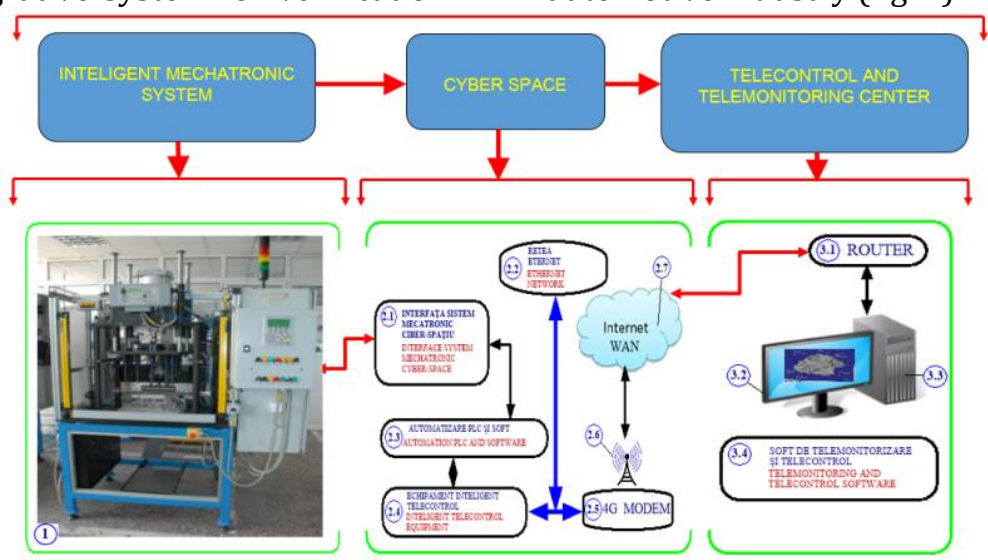

1. Mecatronic System for Tightness Checking INCDMTM

Figure 2: Smart mechatronics and cyber-mixmechatronics integrative system for verification and measurement

Smart mechatronics system and cyber- sensors (multiaplicative in industry) (fig. 3) mixmechatronics architectural system of

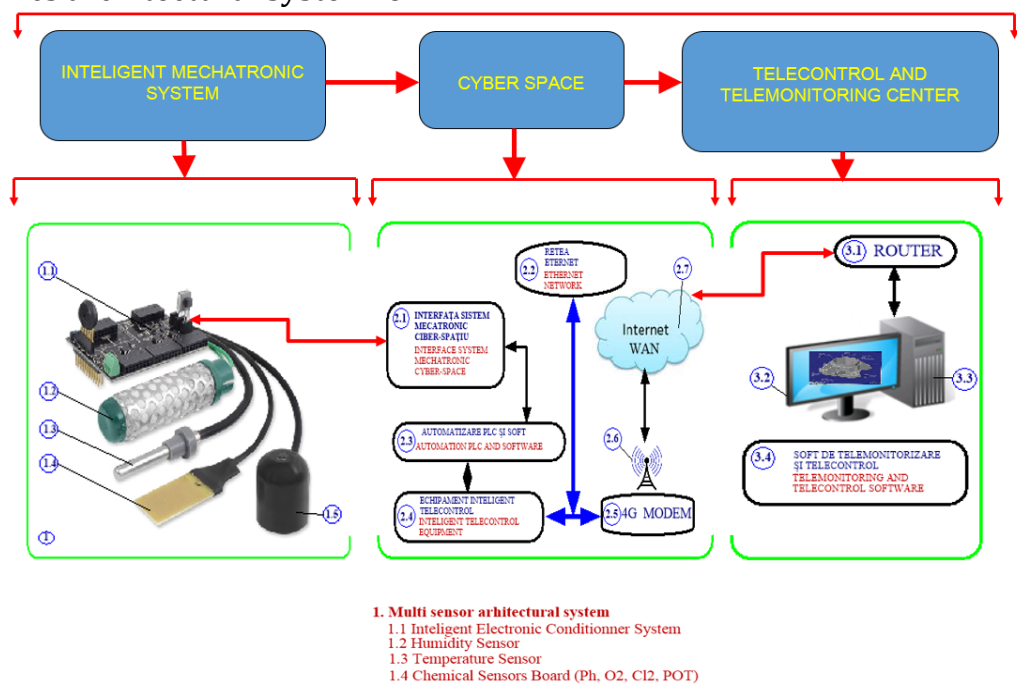

Figure 3: Smart mechatronics system and cyber-mixmechatronics architectural system of sensors

Smart mechatronics system and cyber- welding (industrial multiaplicative) (fig. 4) mixmechatronics integrative system for

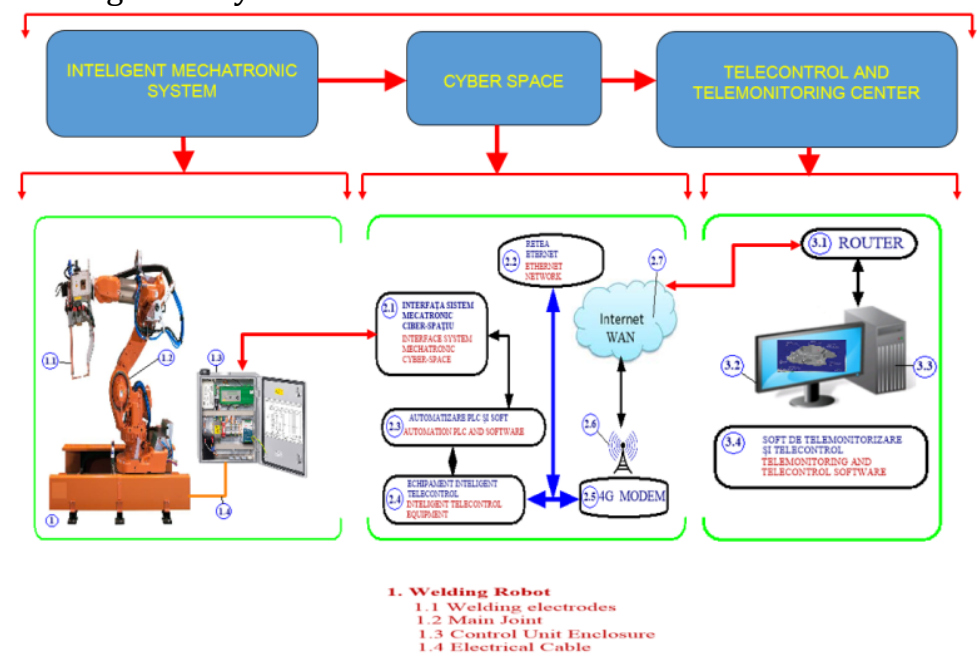

Figure 4: Smart mechatronics system and cyber-mixmechatronics integrative system for welding 
Intelligent mechatronics and cyber- packing/ assembling (mailbox), (multiplicative) mixmechatronics integrative system for (fig. 5)

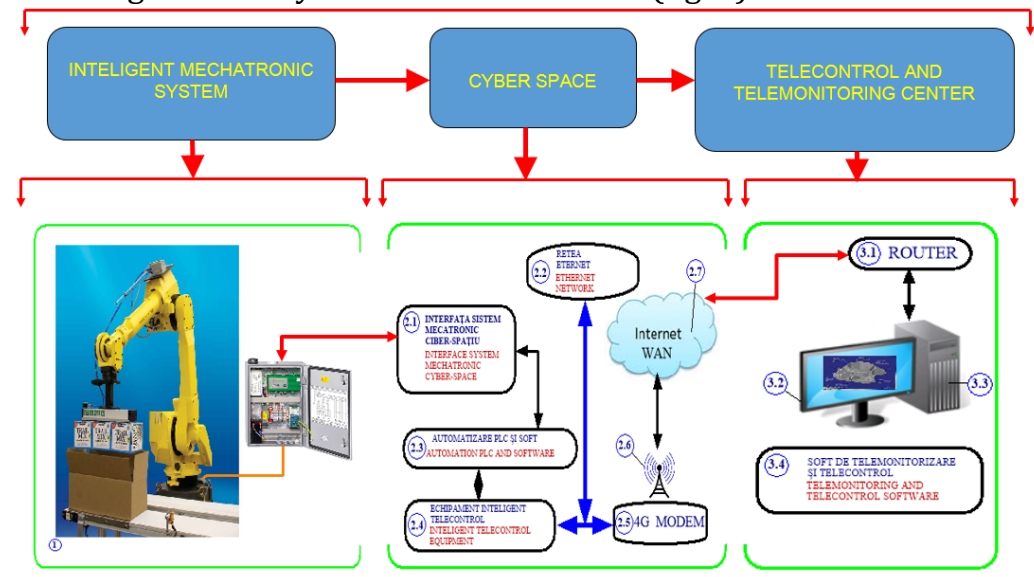

1. Mailbox robot

Figure 5: Intelligent mechatronics and cyber-mixmechatronics integrative system for packing / assembling

Smart mechatronics system and cyber- assistant machine tools (multiaplicative) (fig. mixmechatronics integrative system for 6)

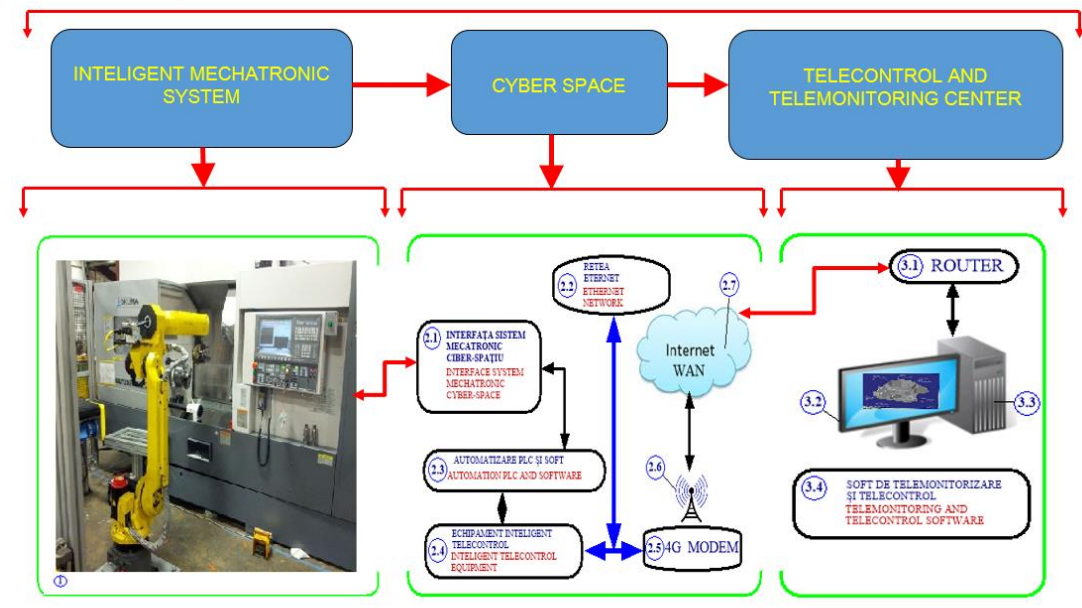

1. Robot Serving Machine Tools

Figure 6: Smart mechatronics system and cyber-mixmechatronics integrative system for assistant machine tools

> Smart mechatronics system and cyber- painting (multiaplicative) (fig. 7) mixmechatronics integrative system for car

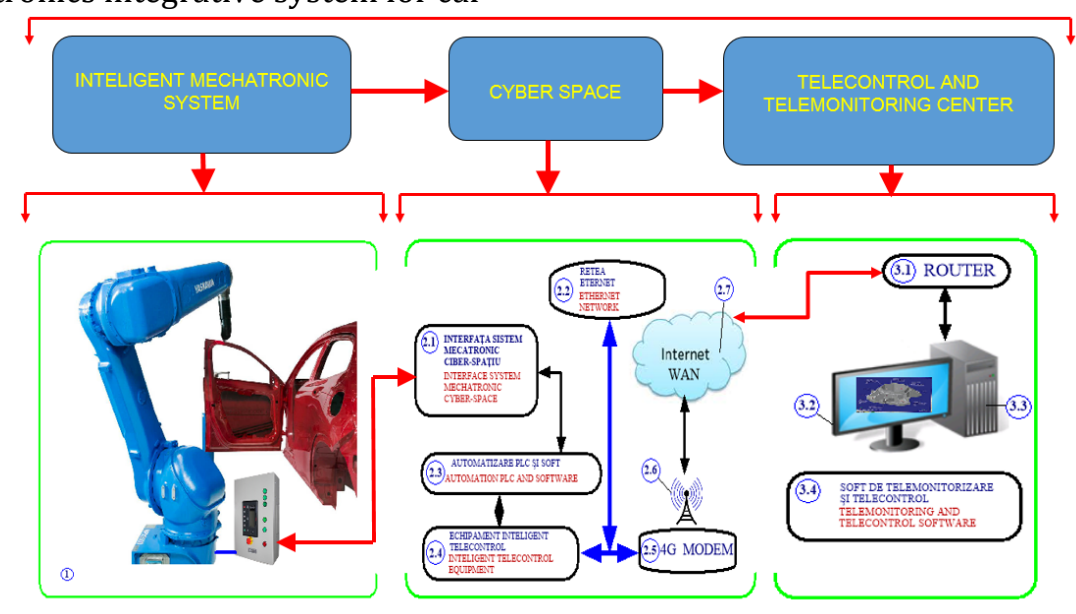

1. Robot Painting Automotive

Figure 7: Smart mechatronics system and cyber-mixmechatronics integrative system for car painting 
Smart mechatronics system and cyber-

dimensional control (multiaplicative) in industry mixmechatronics integrative system for (fig. 8)

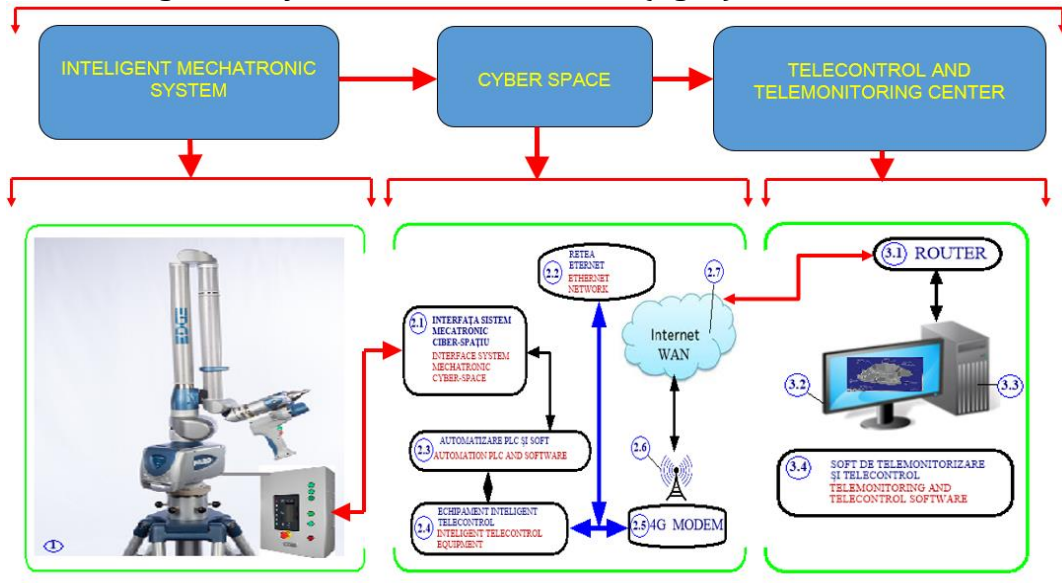

1. Dimensional Control Robot"

Figure 8: Smart mechatronics system and cyber-mixmechatronics integrative system for dimensional control

Smart mechatronics system and cyber- ultraprecise positioning (multiaplicative) mixmechatronics integrative for

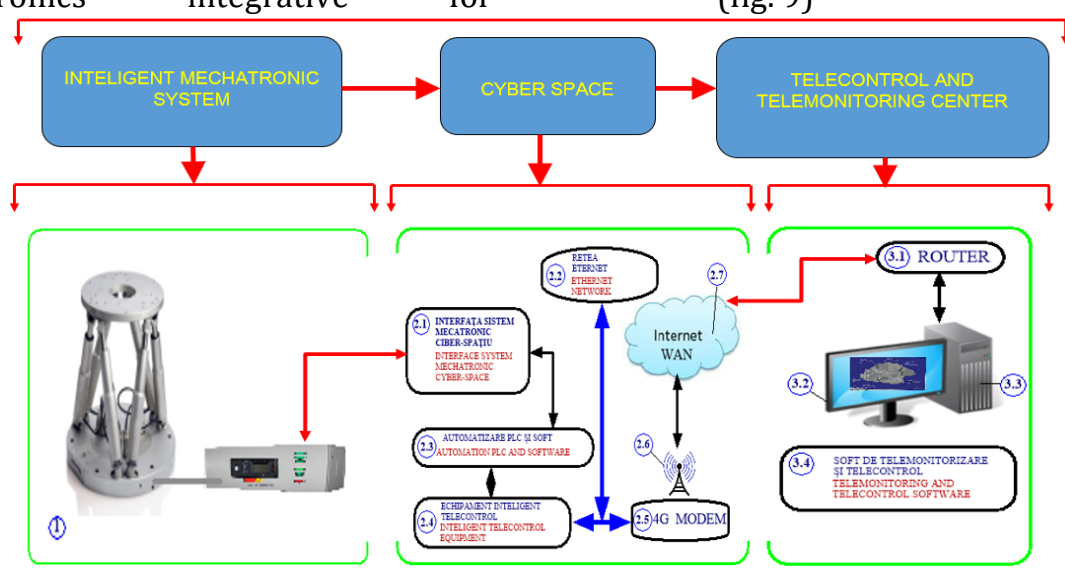

1. Positioning Robot "HEXAPOD"

Figure 9: Smart mechatronics system and cyber-mixmechatronics integrative for ultraprecise positioning

Smart mechatronics system and cyber- medicine(in surgery), (multiaplicative) (fig. mixmechatronics integrative for 10)

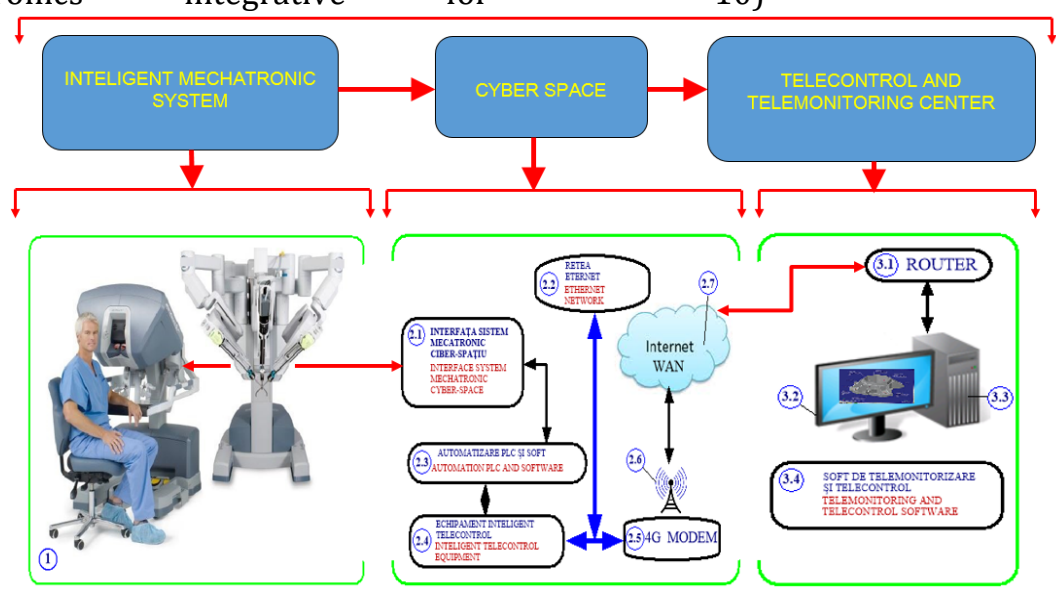

1. Surgical Robot "DaVinci"

Figure 10: Smart mechatronics system and cyber-mixmechatronics integrative for medicine (in surgery) 
Smart mechatronics system and cyber-

$>$ for extinguishing electric fires (fig. 11)

mixmechatronics integrative (Drone type)

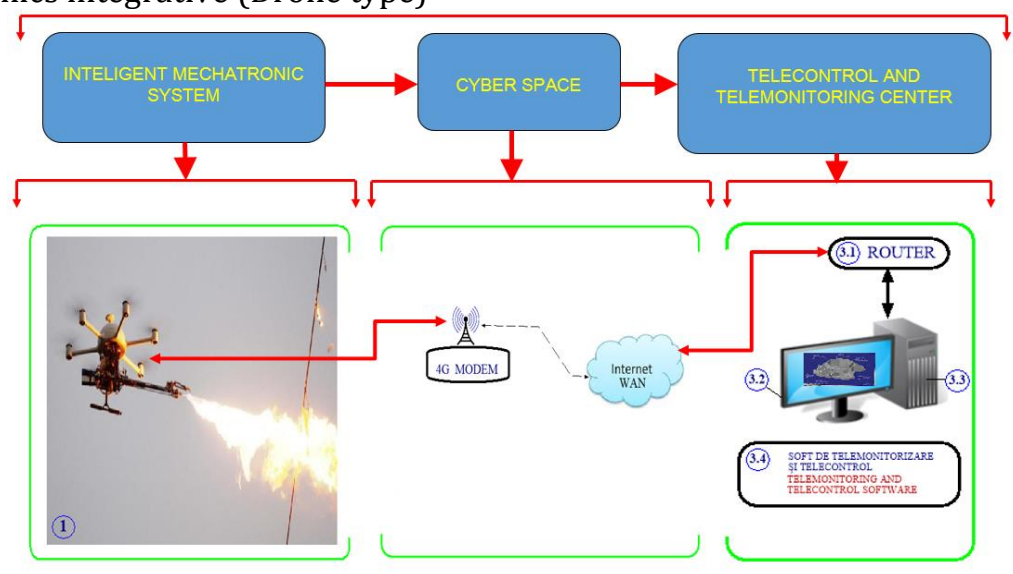

1 Drone for extinguishing electric fires

Figure 11: Smart mechatronics system and cyber-mixmechatronics integrative (Drone type) for extinguishing electric fires

Smart mechatronics system and cyber-mixmechatronics integrative for agriculture (spraying), (fig. 12)

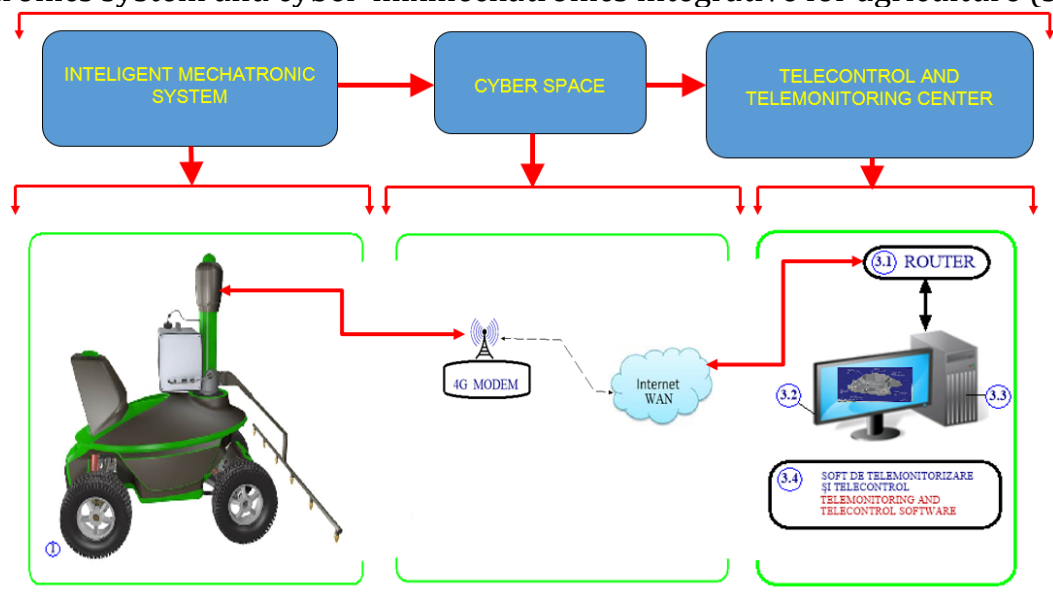

1. Mobile Agrigol Garden Robót

Figure 12: Smart mechatronics system and cyber-mixmechatronics integrative for agriculture (spraying)

Smart mechatronics system and cyber - tasking drones" type (fig. 13)

mixmechatronics integrative, "Smart multi

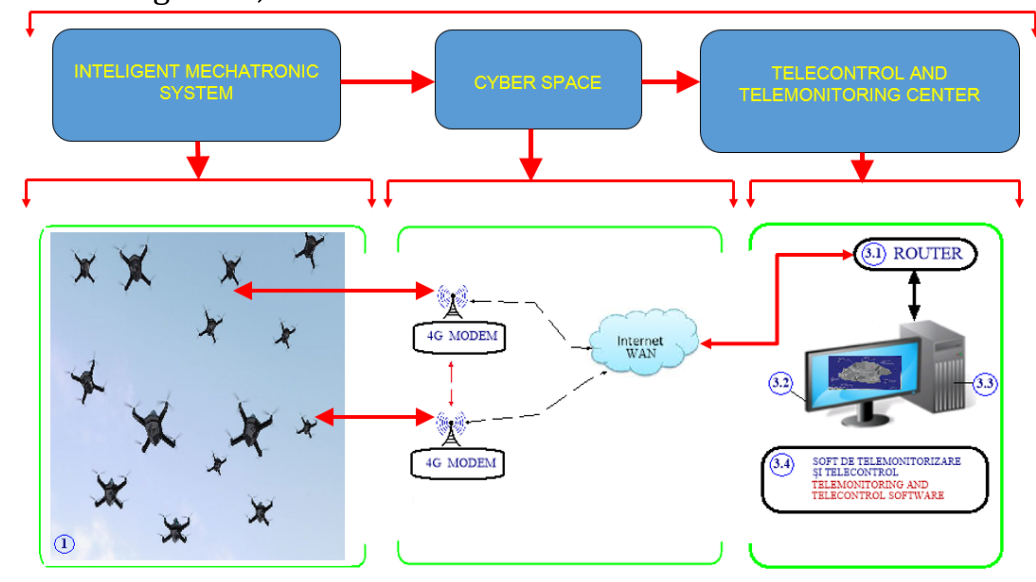

1. Inteligents Drones Roe

Figure13: Smart mechatronics system and cyber-mixmechatronics integrative, "Smart multi tasking drones" type 
Smart mechatronics system and cyber-mixmechatronics integrative for renewable energy (fig. 14)

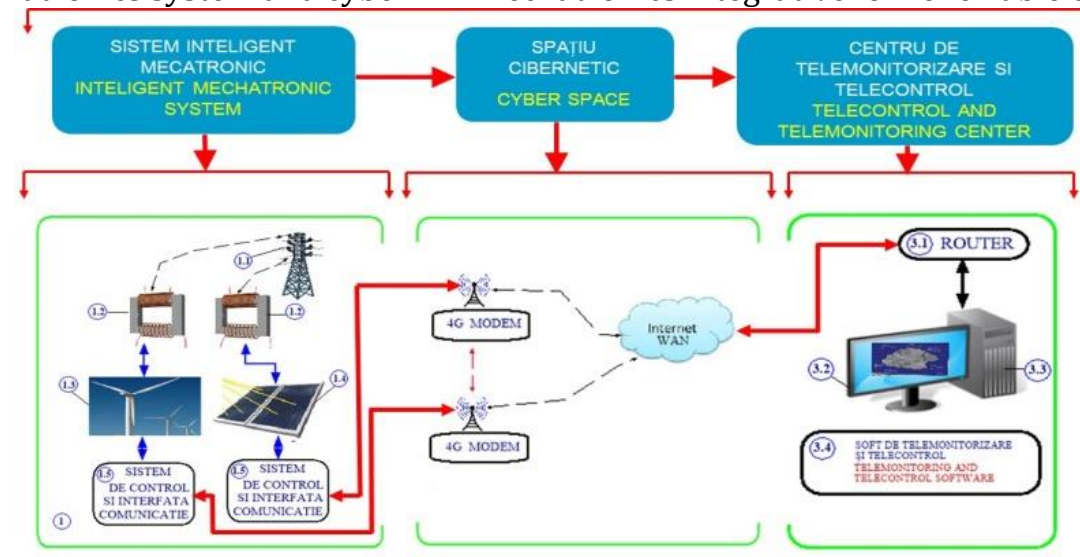

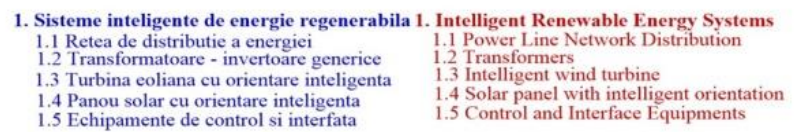

Figure 14: Smart mechatronics system and cyber-mixmechatronics integrative for renewable energy

$>$ Smart mechatronics system and cyber-mixmechatronics integrative for terrestrial telescope network (fig. 15)

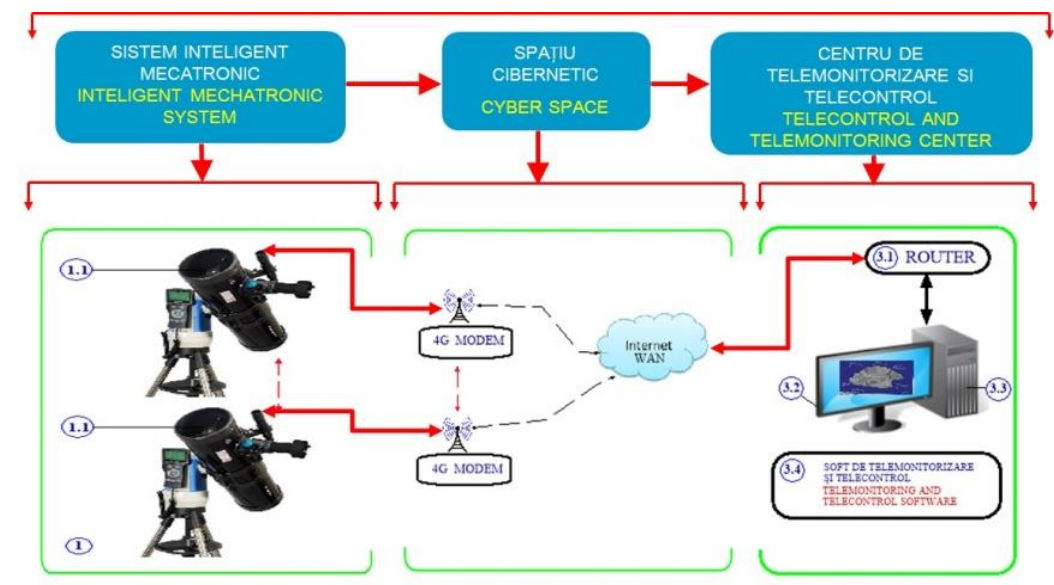

1. RETEA DE TELESCOAPE TERESTRE
1.1 Telescop de Inaltă Rezoluție
1.1 Hight resolution Telescope

Figure 15: Smart mechatronics system and cyber-mixmechatronics integrative for terrestrial telescope network

Smart mechatronics system and cyber-mixmechatronics integrative for automatic waste sorting (fig. 16)

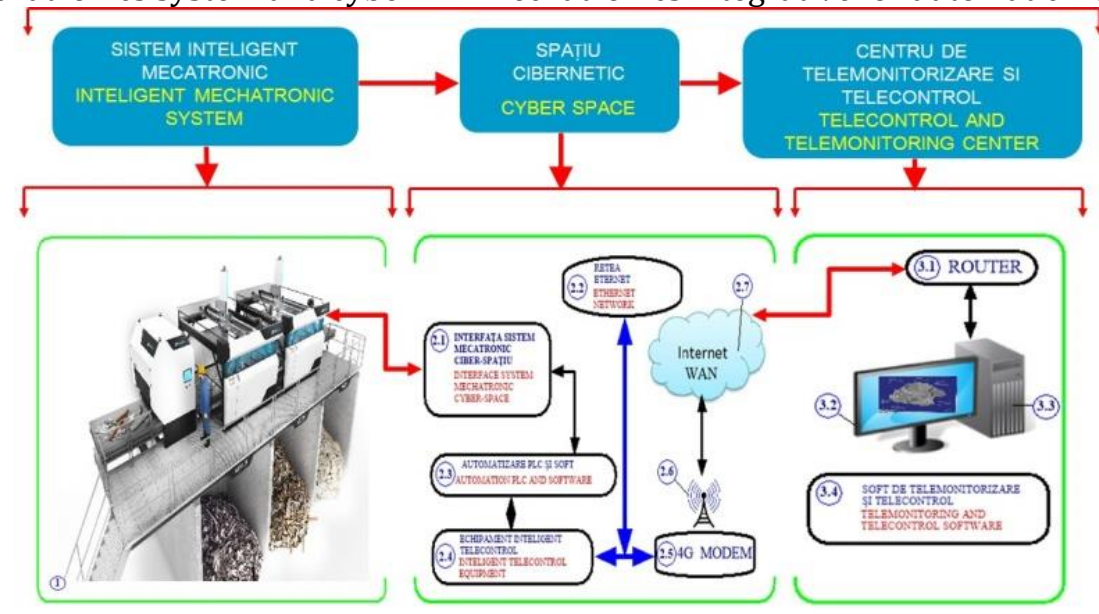

1. Banda Automata de Sortare Deseuri $\quad$ 1. Automatic Waste Sorting Band

Figure 16: Smart mechatronics system and cyber-mixmechatronics integrative for automatic waste sorting 
Smart mechatronics system and cyber-mixmechatronics integrative for network of micronanosatellites (fig. 17)

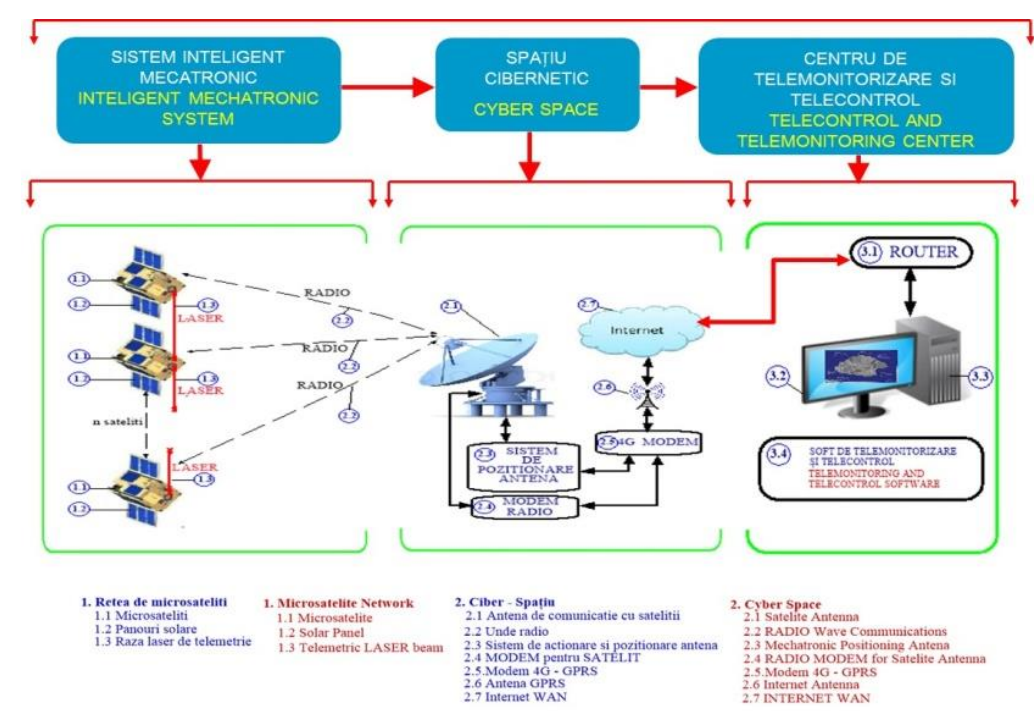

Figure 17: Smart mechatronics system and cyber-mixmechatronics integrative for network of micronanosatellites

- Concepts of activities in Industry 4.0

$>$ "Circle" of activities in Industry 4.0 (fig. 18)

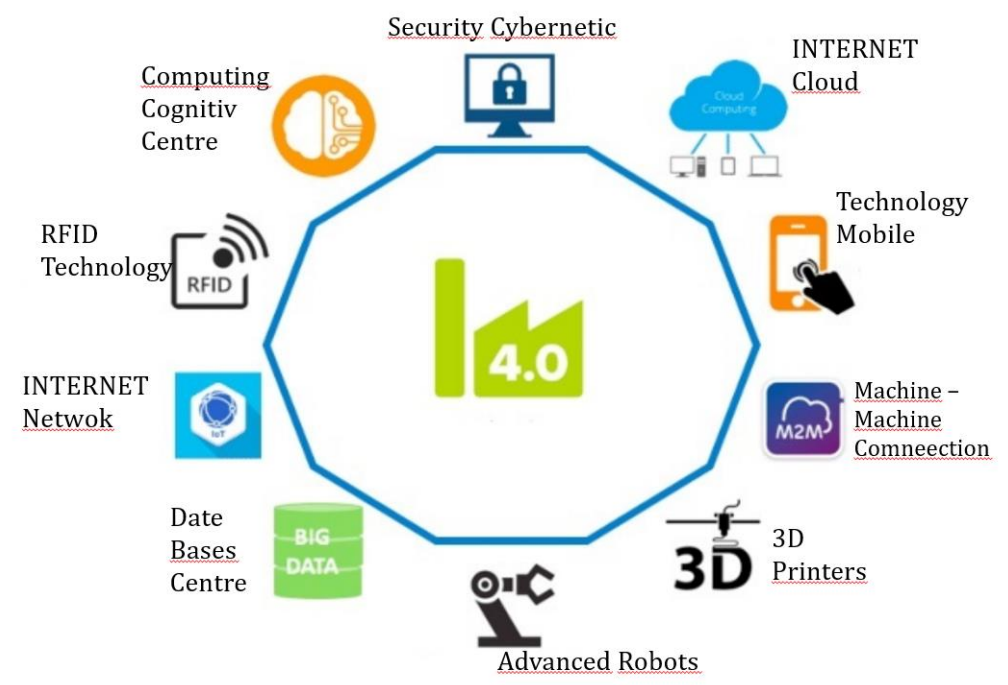

Figure 18. "Circle" of activities in Industry 4.0

"Cube" of activities in Industry 4.0 (fig. 19)

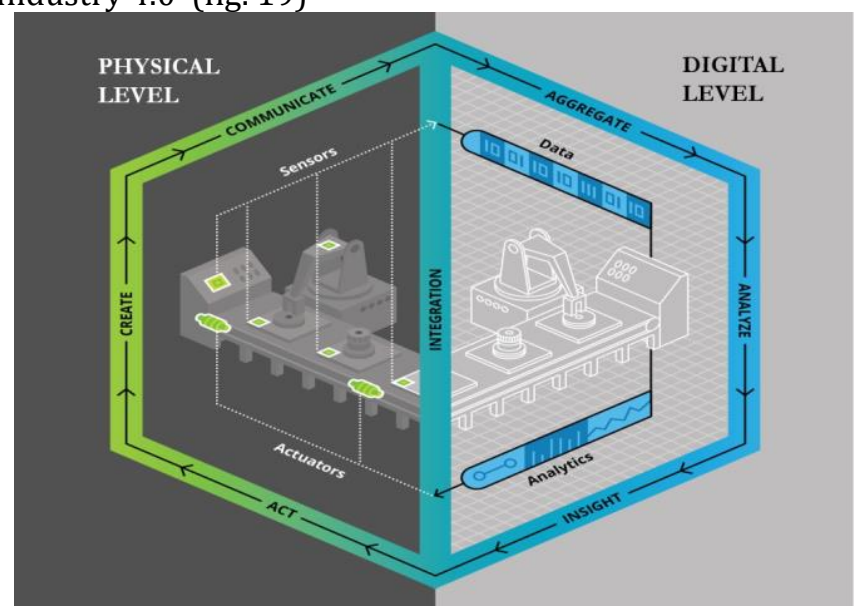

Figure 19: "Cube" of activities in Industry 4.0 
"The arhitecture" of Industry 4.0 (fig. 20)

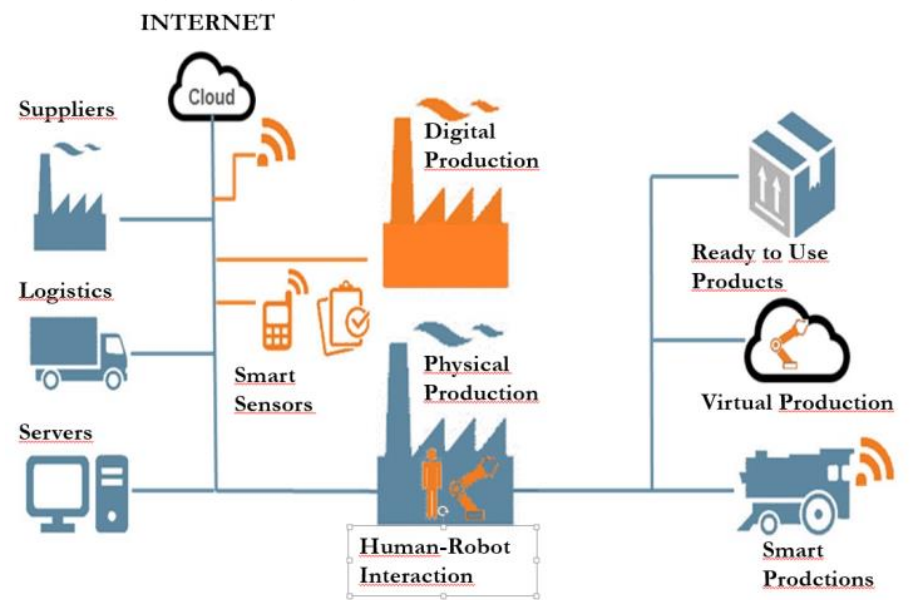

Figure 20: "The arhitecture" of Industry 4.0

Innovative model for pentru Digitizing an enterprise (fig. 21)

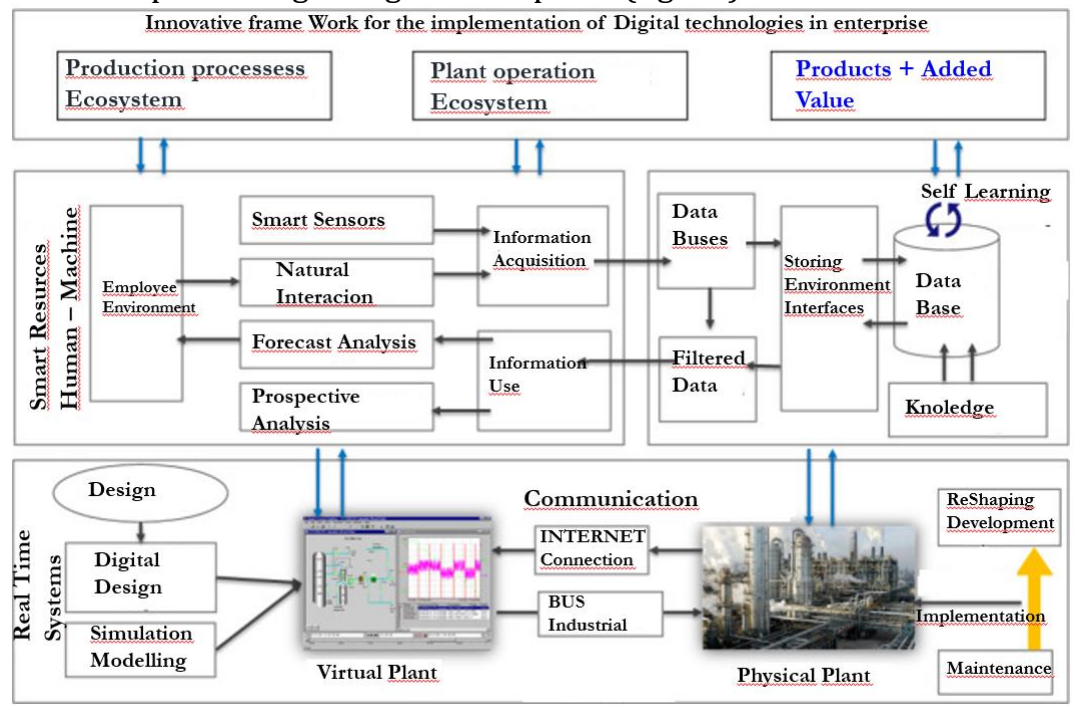

Figure 21: Innovative model for pentru Digitizing an enterprise

Simplified structure Digitizing Enterprise (fig. 22)

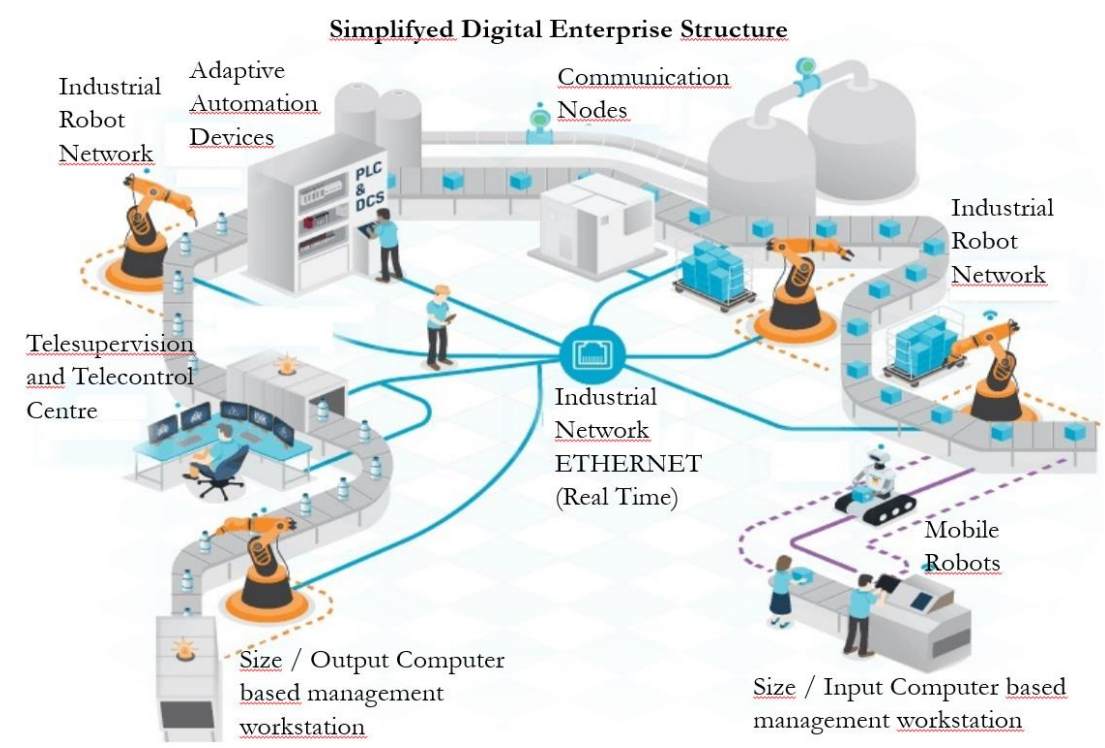

Figure 22: Simplified structure Digitizing Enterprise 
Simplified scheme Automotive Digitized Factory (fig. 23)

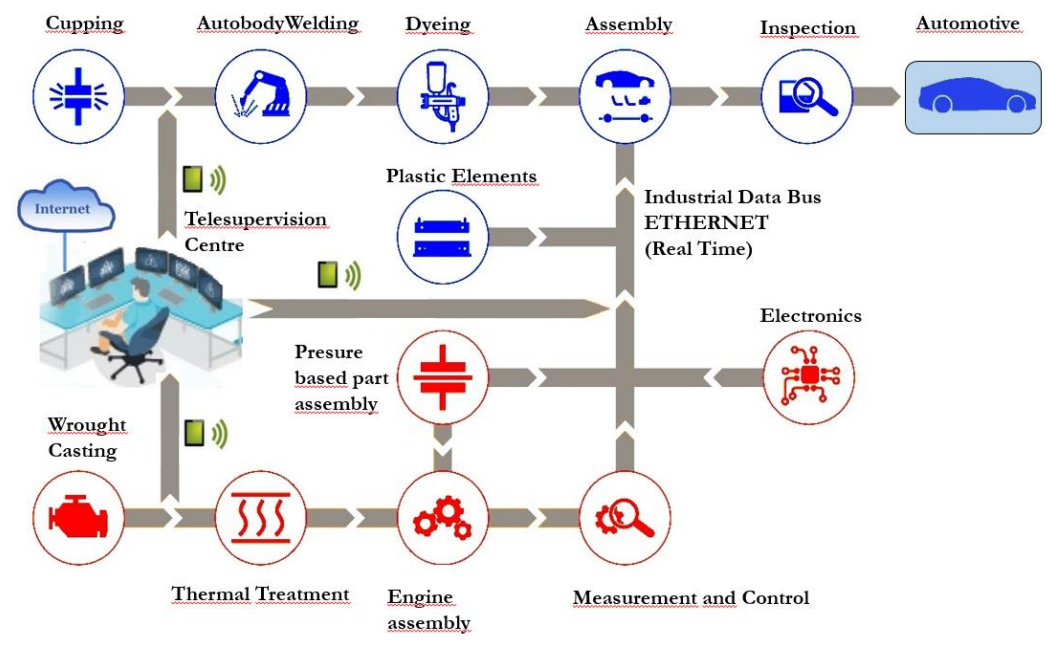

Figure 23. Simplified scheme Automotive Digitized Factory

Simplified scheme Energetic Digitized Factory (fig. 24)

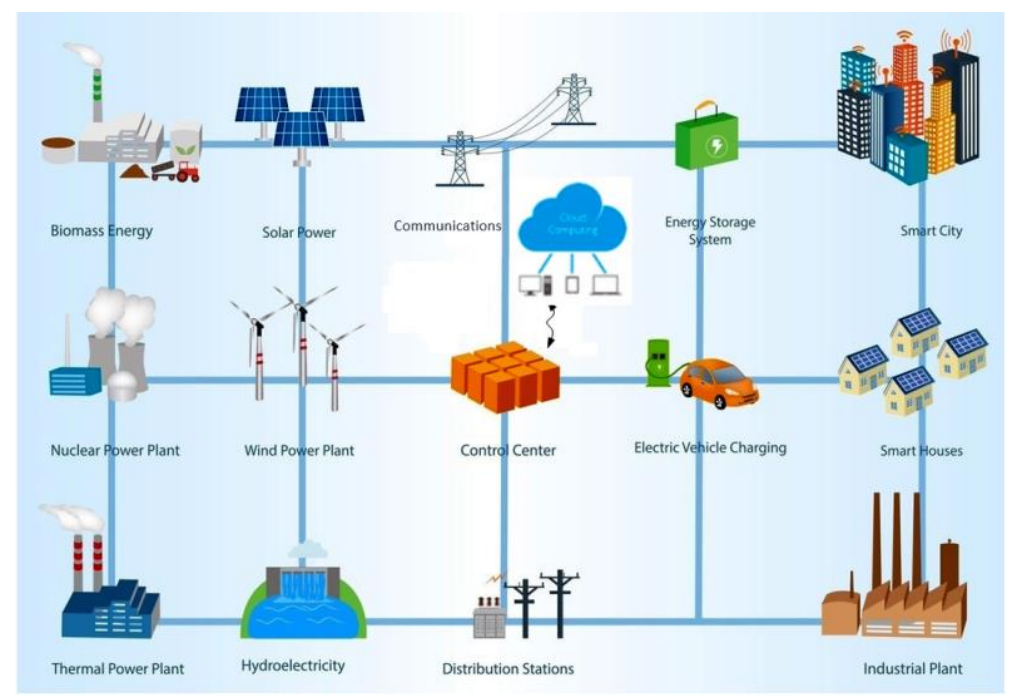

Figure 24. Simplified scheme Energetic Digitized Factory

Simplified scheme Digitized Cheese Factory (fig. 25)

Simplifyed of a Digital Cheese derived products

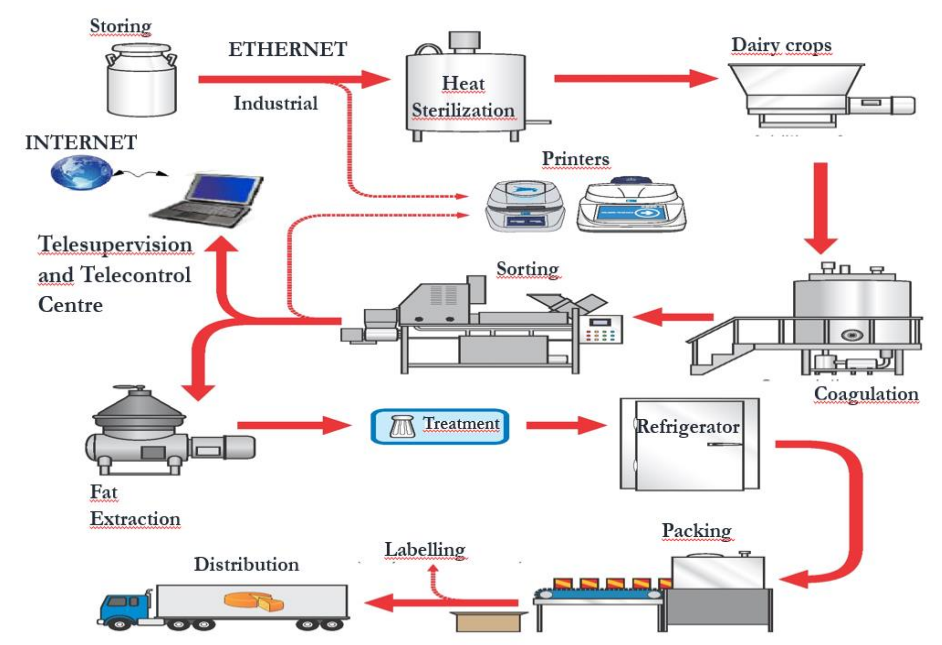

Figure 25. Simplified scheme Digitized Cheese Factory 


\section{The Advantages of Industry 4.0}

- time: Each employee becomes more efficient, productive and qualitative;

- minimal cost: through very precise data in the right and necessary context;

- Flexibility: by creating flexible systems ready for change and for new opportunities;

- integration: digital manufacturing involves the simultaneous development of the product and the production process.

\subsection{The Advantages of Romania in the perspective of Industry 4.0}

Romania is in a favorable position for Industry 4.0, as follows:

- Represents the best destinations for investments in new production facilities, by returning industrial production to Europe;

- has the well developed automotive industy, with a wide chain of suppliers in the field;

- has the fastest internet connection from Europe;

- there are in România, many specialized firms in TIC, many research institutes, with domains in Mechatronics and Cyber-Mix-Mechatronics and staff with professional skils;

- etc.

\section{Conclusions}

The scientific paper shows that industrial digitization will have both a horizontal and a vertical impact on the value chain, which implies that on the one hand companies need to integrate and digitize their vertical data flow much better to the development of products and purchases to the processing and logistics of transport, and on the other hand, presupposes a horizontal collaboration with key suppliers, customers and other partners in the value chain.

Companies, businesses and industry in general in Industry 4.0 should be involved in the development and deployment of complex digital solutions, and all committed staff have total confidence that industrial digitization is the most appropriate and necessary choice for the future.

The scientific work also synthesizes the beginnings of industrial digitization by introducing intelligent concepts and solutions proposed by the author for mechatronic and cyber-mixmechronic integrated systems that are or are to be implemented in different industrial sectors (automobiles, aerospace, agriculture, medicine, etc.) from Romania

\section{References}

[1] Gheorghe, Gheorghe. Study and analyse regarding the concepts of mechatronics and adatronics virtual models and cyber-mechatronics and cyberadaptronics. Bucharest, Cefin Publishing House, 2016.

[2] Gheorghe, Gheorghe Elaboration of new scientific and technological concepts and new virtual mechatronics and adaptronics models and cybermechatronics and cyber-adaptronics, Bucharest, Cefin Publishing House, 2016.

[3] Noble, B., Flinn, J. " Wireless, self-organizing cyberphysical systems." Proc. of the NSF Workshop on CyberPhysical Systems. Austin, TX (2007).

[4] Pop, L., Matiec, V Transdisciplinary Approach of the Mechatronics in the Knowledge-based Society, Advances in Mechatronics. H. Martinez-Alfar (Ed.), InTech, 2011. 